\title{
Role of Albuminuria in Detecting Cardio-Renal Risk and Outcome in Diabetic Subjects
}

\author{
Pia Clara Pafundi ${ }^{1,+}+^{\mathbb{D}}$, Carlo Garofalo ${ }^{1,+}{ }^{+}$, Raffaele Galiero ${ }^{1,+}{ }^{+}$, Silvio Borrelli ${ }^{1} \mathbb{D}$, Alfredo Caturano ${ }^{1} \mathbb{D}$, \\ Luca Rinaldi $^{1}{ }^{\mathbb{D}}$, Michele Provenzano ${ }^{2}{ }^{(\mathbb{D}}$, Teresa Salvatore ${ }^{3}$, Luca De Nicola ${ }^{1} \mathbb{D}$, Roberto Minutolo ${ }^{1, *} \neq$ \\ and Ferdinando Carlo Sasso $1, *, \pm \mathbb{D}$
}

1 Department of Advanced Medical and Surgical Sciences, University of Campania Luigi Vanvitelli, Piazza Luigi Miraglia 2, 80138 Naples, Italy; piaclara.pafundi@unicampania.it (P.C.P.); carlo.garofalo@unicampania.it (C.G.); raffaele.galiero@unicampania.it (R.G.); dott.silvioborrelli@gmail.com (S.B.); alfredo.caturano@unicampania.it (A.C.); luca.rinaldi@unicampania.it (L.R.); luca.denicola@unicampania.it (L.D.N.)

2 Renal Unit, Department of Health Sciences, “Magna Graecia” University, Viale Europa, 88100 Catanzaro, Italy; michiprov@hotmail.it

3 Department of Precision Medicine, University of Campania Luigi Vanvitelli, Via De Crecchio 7, 80138 Naples, Italy; teresa.salvatore@unicampania.it

* Correspondence: roberto.minutolo@unicampania.it (R.M.); ferdinando.sasso@unicampania.it (F.C.S.)

+ R.G., P.C.P. and C.G. (co-first authors) equally contributed to the draft of the manuscript.

$\ddagger \quad$ R.M. and F.C.S. are co-last and co-corresponding authors.

check for updates

Citation: Pafundi, P.C.; Garofalo, C.; Galiero, R.; Borrelli, S.; Caturano, A.; Rinaldi, L.; Provenzano, M.; Salvatore, T.; De Nicola, L.; Minutolo, R.; et al. Role of Albuminuria in Detecting Cardio-Renal Risk and Outcome in Diabetic Subjects. Diagnostics 2021, 11, 290. https://doi.org/10.3390/ diagnostics 11020290

Academic Editor: Simona Bungau

Received: 28 January 2021

Accepted: 10 February 2021

Published: 12 February 2021

Publisher's Note: MDPI stays neutral with regard to jurisdictional claims in published maps and institutional affiliations.

Copyright: (c) 2021 by the authors. Licensee MDPI, Basel, Switzerland. This article is an open access article distributed under the terms and conditions of the Creative Commons Attribution (CC BY) license (https:/ / creativecommons.org/licenses/by/ $4.0 /)$.
Abstract: The clinical significance of albuminuria in diabetic subjects and the impact of its reduction on the main cardiorenal outcomes by different drug classes are among the most interesting research focuses of recent years. Although nephrologists and cardiologists have been paying attention to the study of proteinuria for years, currently among diabetics, increased urine albumin excretion ascertains the highest cardio-renal risk. In fact, diabetes is a condition by itself associated with a highrisk of both micro/macrovascular complications. Moreover, proteinuria reduction in diabetic subjects by several treatments lowers both renal and cardiovascular disease progression. The 2019 joint ESC-EASD guidelines on diabetes, prediabetes and cardiovascular (CV) disease assign to proteinuria a crucial role in defining CV risk level in the diabetic patient. In fact, proteinuria by itself allows the diabetic patient to be staged at very high $\mathrm{CV}$ risk, thus affecting the choice of anti-hyperglycemic drug class. The purpose of this review is to present a clear update on the role of albuminuria as a cardio-renal risk marker, starting from pathophysiological mechanisms in support of this role. Besides this, we will show the prognostic value in observational studies, as well as randomized clinical trials (RCTs) demonstrating the potential improvement of cardio-renal outcomes in diabetic patients by reducing proteinuria.

Keywords: type 2 diabetes; albuminuria; cardiovascular risk; renal outcome

\section{Introduction}

The clinical significance of albuminuria in diabetic subjects and the impact of its reduction on the main cardio-renal outcomes through the use of different drug classes represent one of the most interesting research focuses of the last years. The loss of glomerular selective filtration, the initial expression of renal damage and the consequent progression of chronic renal failure (CKD) have led to proteinuria being considered a complex marker of both nephropathy and cardiovascular (CV) risk [1-3]. In fact, the initial concept of glomerular damage was associated with the tubular damage caused by the pathological presence of proteins in the pre-urine, with consequent inflammatory activation of the tubule and alteration of the tubulo-glomerular feedback and electrolytes imbalance. On the other hand, albuminuria is associated with endothelial damage, which determines a high $\mathrm{CV}$ risk $[4,5]$. 
Therefore albuminuria, even at the lower concentrations represented by microalbuminuria (urine albumin/creatinine ratio-UACR-30-300 mg/g), is an important cardio-renal risk marker.

Although nephrologists and cardiologists have been paying attention to the study of proteinuria for years, type 2 diabetes mellitus (T2DM) is currently considered a condition in which increased urine albumin excretion ascertainsthe highest cardio-renal risk [6-8]. In fact, diabetes is a condition by itself associated, through various mechanisms [9-11], with a high risk of both micro- and macrovascular complications [12-16]. Moreover, proteinuria reduction in diabetic subjects by several treatments lowers the risk of both renal and cardiovascular disease progression [17].

Therefore, The 2019 joint ESC-EASD guidelines on diabetes, prediabetes and cardiovascular disease assign to proteinuria a crucial role in defining the level of CV risk in diabetic patients [18]. In fact, proteinuria is considered to target organ damage, and alone it is enough to stage the diabetic patient at very high CV risk, thus affecting the choice of anti-hyperglycemic drug class.

The purpose of this review is to present a clear update on the role of albuminuria as a cardio-renal risk marker, starting from pathophysiological mechanisms in support of this role. Besides this, we will show its prognostic value in observational studies and how randomized clinical trials (RCTs) have demonstrated the potential improvement of cardio-renal outcomes in diabetic patients by reducing proteinuria.

\section{Pathophysiological Role of Albuminuria in Cardio-Renal Damage}

Recently, several potential biomarkers seem to play a role in both the onset and progression of diabetic nephropathy (DN) (e.g., microRNAs, exosomes, long noncoding RNAs, and microparticles) [19]. These are accompanied by other well-known markers suggestive of different types of renal damage: glomerular (Transferrin, Type IV collagen, Cystatin C), tubular (liver-type fatty acid-binding protein "L-FABP", neutrophil gelatinase-associated lipocalin "NGAL", kidney injury molecule-1 "KIM-I", $\alpha 1$-microglobulin, fibroblast growth factor 23 "FGF 23"), fibrosis (transforming growth factor- $\beta 1$ "TGF- $\beta 1$ ", connective tissue growth factor "CTGF"), oxidative stress (8-hydroxy-2'-deoxyguanosine "8-OHdG") and inflammation (monocyte chemoattractant protein-1 "MCP-1", IL-1, IL-6, IL-18, TNF- $\alpha$ ). In particular, given the known crucial role of oxidative stress in the development of vascular damage in T2DM, it is not clear how its products could be included among markers of renal damage. Many studies have shown a potential self-sustainment of reactive oxygen species (ROS) on both inflammatory damage and cardiovascular risk. In fact, ROS scavenges nitric oxide (NO) and peroxy-nitrite, which are increased in diabetic patients, resulting in a reduced NO bioavailability. Among the other products of oxidative stress in T2DM, the advanced glycation end-product (AGEs) can stimulate the production of free radicals, which seems closely related to the endothelial damage found in patients with CKD [20,21]. However, albuminuria/proteinuria still remains the most widely used marker of DN in both clinical practice and clinical trials, likely because microalbuminuria from the 1980s has been described not only as a renal, though also as a CV risk factor in diabetic patients [22]. Moreover, almost at the same time, proteinuria has been reported as a relevant risk marker of CV mortality in the general population [23].

The absence of proteins, particularly of albumin, is an expression of both the integrity of the glomerular apparatus and the ability of the proximal tubule to absorb the modest quantities of albumin physiologically present in the glomerular filtrate. Therefore, a progressive increase in albuminuria excretion determines both glomerular damage due to the effect on mesangium and tubular damage due to excessive albumin absorption with inflammatory phenomena of the interstitium, resulting in an overall functional renal damage [24].

The link between renal and cardiovascular damage is explained by the Steno hypothesis, in which albumin escape is considered an expression of endothelial damage, with increased systemic vascular permeability $[25,26]$. Systemic vascular damage involves 
both glomerular and, subsequently, tubular damage, with consequent albuminuria and renal alteration, and at the same time, the endothelial damage causes increased CV risk (Figure 1).

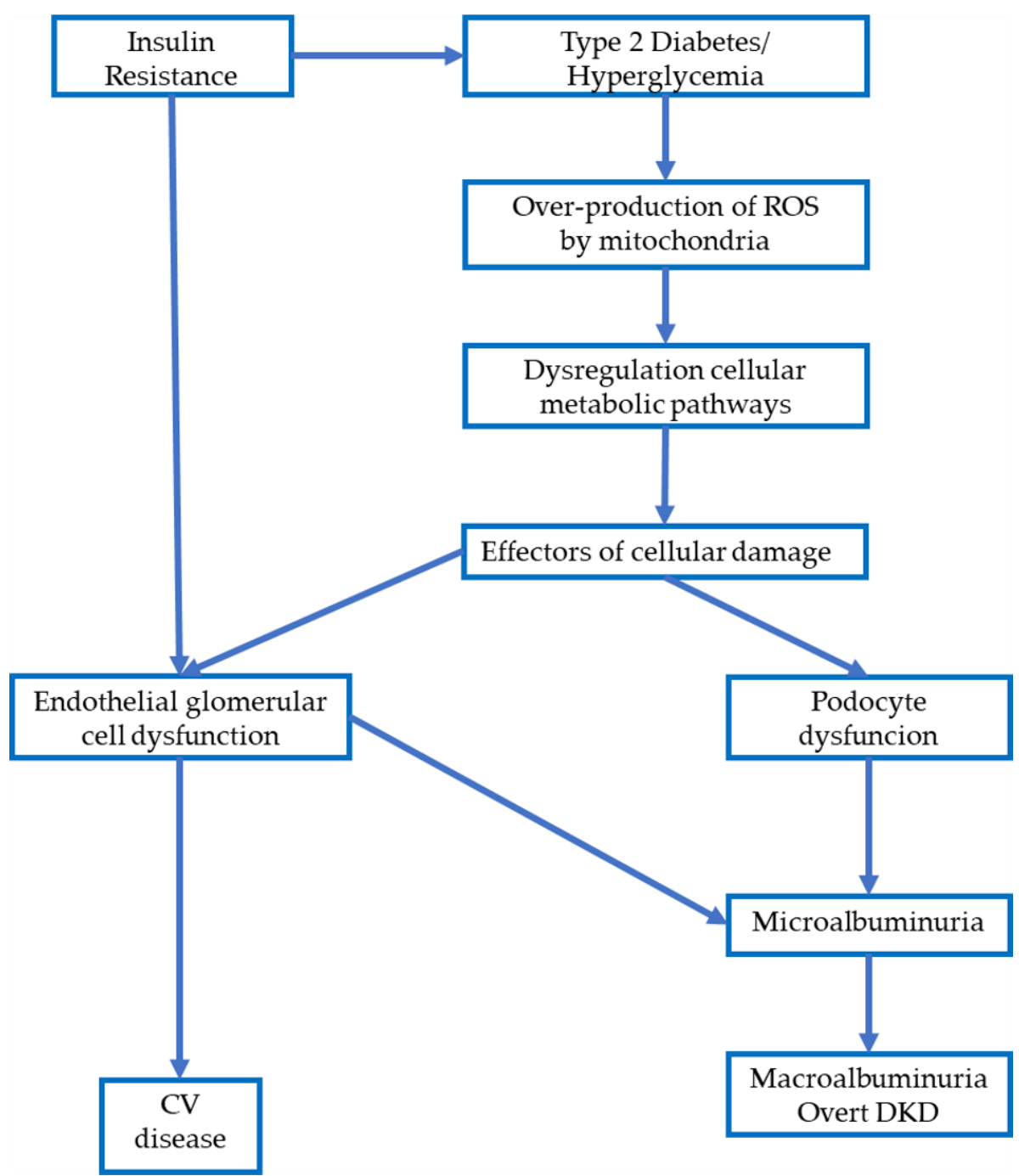

Figure 1. Pathophysiological cascade that describes the relationship between diabetes, endothelial damage, microalbuminuria, Diabetic Kidney Disease (DKD) and cardiovascular (CV) disease.

Intriguingly, whether albuminuria is the cause or consequence of cardio-renal damage is currently an object of study. More recently, the hypothesis of a nonalbuminuric pattern in Diabetic Kidney Disease (DKD) has become much more challenging. Several studies, indeed, have shown that diabetic patients may develop a progressive end-stage chronic kidney disease regardless of albuminuria [27]. Moreover, as in the albuminuric pattern, these patients also seem more prone to developing CV events, particularly described as myocardial infarction and ictus, as compared to the general population [28]. Another interesting hypothesis, based on both experimental [29,30] and clinical data [31], is that variations in albumin excretion rate (AER) are constant with age and appear to have an individual character. The ability of the endothelium to regulate vascular tone through nitric oxide (NO) affects the predisposition to future renal damage [29,30]. Therefore, in "healthy" subjects, the different levels of albuminuria express different physiological conditions, as well as a predisposition to future renal and/or CV damage mediated by endothelial dysfunction [32]. Therefore, despite many other markers of glomerular and tubular damage that have been proposed, albuminuria still represents the main one suggestive at the same time, especially in diabetes mellitus, of both renal and cardiovascular damage. 


\section{Glomerular Mechanisms of Albuminuria}

A central pathophysiological role in the onset and progression of micro- and subsequent macroalbuminuria/overt proteinuria is damage to the glomerular endothelium [33]. The impairment of the endothelial glycocalyx mediated by various mechanisms represents an early event of diabetic glomerular damage. Its effectors include vascular endothelial growth factor (VEGF), reactive oxygen species (ROS), inflammatory cytokines, endothelin-1 (ET-1), ET-1/endothelin receptor A (ETA) and Endothelial Nitric Oxide Synthase (eNOS). Similarly, there is a cross-talk between glomerular endothelial cells and mesangial cells, mainly mediated by platelet-derived growth factor-beta (PDGF- $\beta$ )/PDGF-R [34] (Figure 2).

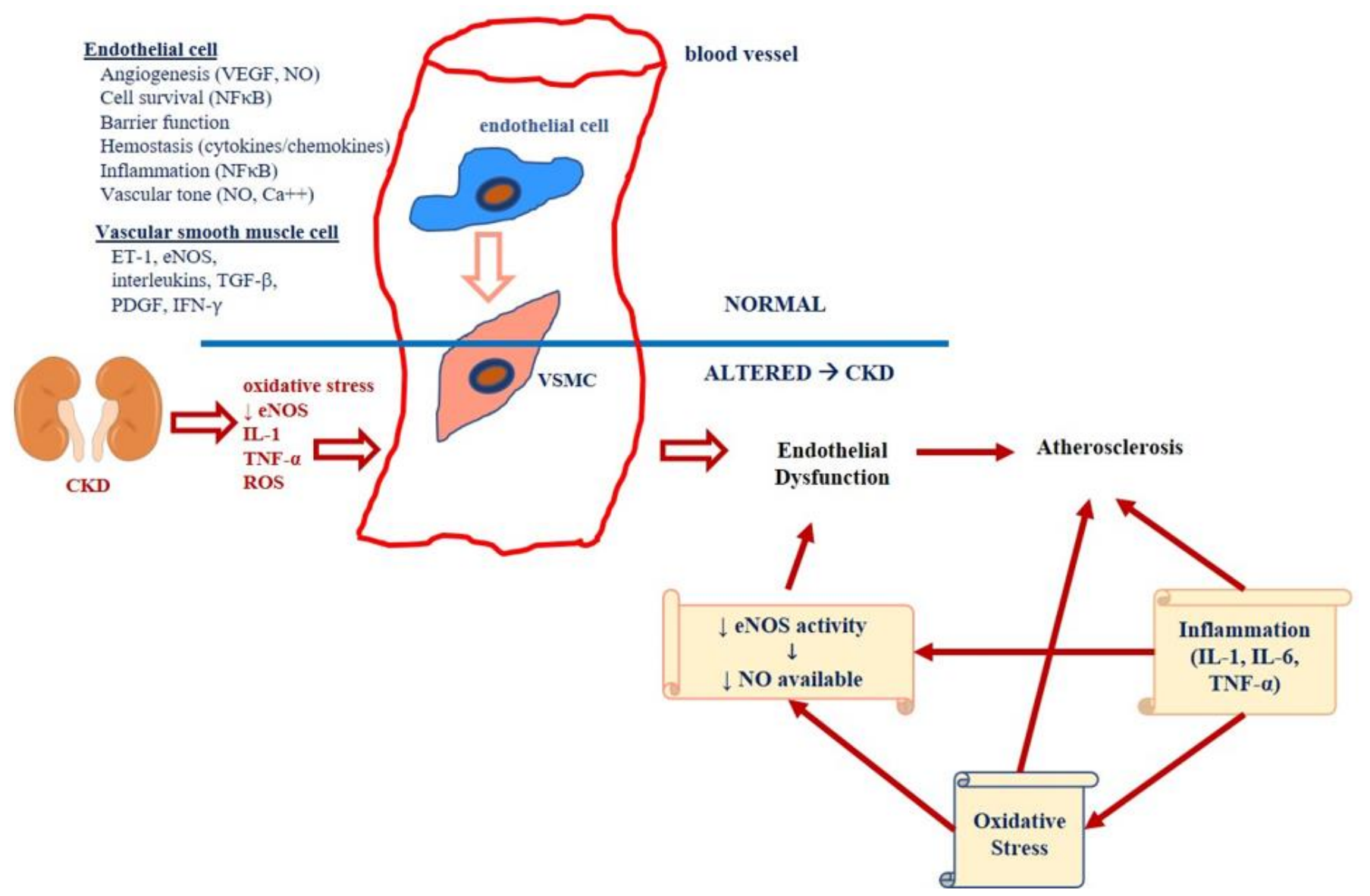

Figure 2. Effect of chronic kidney disease (CKD)-related factors on the vascular endothelium. Oxidative mediators involved in endothelial cell and vascular smooth muscle cell function and relationship with Chronic Kidney Disease (CKD). Abbreviations: eNOS, endothelial nitric oxide synthase; IL-, interleukin-; IL6, interleukin6; NF- $\mathrm{B}$, nuclear factor kappa-light-chain-enhancer of activated B cell; NO, nitric oxide; TNF, tumor necrosis factor-alpha; NO, nitric oxide; ET-1, endothelin 1; PDGF, platelet-derived growth factor; IFN- $\gamma$, interferon-gamma; TGF- $\beta$, tumor growth factor-beta; VEGF, vascular endothelial growth factor.

Moreover, all these factors and others released by the activated endothelium (e.g., ICAM-1, VCAM-1, vWF and matrix metalloproteinases) can induce an activation of the NF-kBintracellular pathway, thus determining an alteration of both intercellular cross-talk and cytoskeleton. This damage has been observed in several chronic diseases, such as CKD and heart failure [20]. The alteration of this cross-talk between endothelial cells and these other glomerular cells favors and increases endothelial damage. In fact, the increase in proteinuria is accompanied by morphological changes of the glomerulus, particularly lesion and loss of podocytes.

The podocyte injury in turn increases endothelial cell damage, thus creating a vicious cycle. 
These morpho-functional changes are due both to the effects of hyperglycemia and the increased permeability of the glomerular filtration barrier to serum proteins [35].

This pathophysiological network confirms Steno's hypothesis, indicating the alteration of the endothelial glycocalyx as the cause of both albuminuria and systemic endothelial dysfunction.

Glycocalyx dysfunction plays a central role in the development of vascular diseases, both micro- and macrovascular. Therefore, microalbuminuria is correctly considered a marker of generalized endothelial damage. Therefore, it can be used in clinical practice both as a predictor of the overall CV risk and, in the event of its reduction with therapeutic interventions, as an indicator of the reduction of CV risk [36], as well as of renal damage.

Recently, podocyte mitochondria have been reported to exert a key role in the development of proteinuria. Various types of damage can occur to podocytes, from hypertrophy to apoptosis, with a consequent reduction in the number of podocytes. This phenomenon contributes to the loss of the selective permeability of the glomerular membrane and consequent proteinuria.

Mitochondrial dysfunction of podocytes can be triggered by various mechanisms: the reduction of oxygen utilization at the mitochondrial level, ROS increase with consequent oxidative damage, advanced glycation end-products (AGEs) accumulation and endoplasmic reticulum stress. These mechanisms involve an alteration of intracellular homeostasis with consequent cell death. Several signaling pathways seem entangled in the genesis of damage to podocytes' mitochondria and consequent proteinuria in Diabetic Kidney Disease (DKD), particularly the mammalian target of rapamycin (mTOR), Wnt/ $\beta$-catenin and AMPK signaling pathways [37,38].

Furthermore, recently, a strict involvement of NLR family pyrin domain containing 3 (NLRP3) Inflammasome in several pathophysiological processes has been described, which leads to podocyte injury and plays a central role in albuminuria [39].

Therefore, both glomerular and cardiovascular damage can arise from a lesion of endothelial glycocalyx, mediated by various inflammatory effectors and triggered by hyperglycemia and elevated permeability. Once activated, this mechanism would portend to self-sustenance, and the consequent podocytes lesion would become responsible for the loss of proteins.

\section{Tubular Mechanisms of Albuminuria}

In recent years, in the pathogenesis of proteinuria, a strict interaction of the glomerulus and the proximal tubule in DKD has been described.

In experimental models of diabetes, a reduced reabsorption of albumin in the proximal tubules (PT) was observed as compared to control animals, which could partly be explained by a reduced albumin endocytosis by PT [40]. This "recovery hypothesis" has been confirmed more recently. Russo et al. have further elucidated the role of tubular reabsorption in the pathogenesis of albuminuria, observing that a large amount of albumin filtered from the glomerulus underwent a rapid recovery process by endocytosis from PT cells [41]. This finding was later confirmed in an experiment on rats rendered nephrotic by puromycin [42].

Interestingly, a role of the endocannabinoid system in the physiology of tubular epithelial cells has been described. In particular, in diabetes, we observe an increase in circulating endocannabinoids, with altered expression of their receptors in tubular epithelial cells and consequent cell damage ranging from hypertrophy to cellular dysfunction [43]. This involvement of endocannabinoids is very intriguing because their role in insulin resistance has been described [44].

Moreover, tubular involvement, especially in DKD, is worthy of utmost attention because, unlike tubular morphological changes, tubular injury is associated with the degree of renal dysfunction [45]. 
On the one hand, these hypotheses would confirm the close relationship between glomerular and tubular damage and, on the other, show the role of specific mediators for tubular damage.

\section{Prognostic Role of Albuminuria on Cardio-Renal Risk}

Abnormal albuminuria, defined as a value $\geq 30 \mathrm{mg} /$ day, is an essential marker for staging chronic kidney disease (CKD) [46] and a recognized and powerful risk factor for adverse clinical outcomes in different settings, such as general population and patients with either T2DM, hypertension or CKD [47-51].

In the general population, the prevalence of abnormal albuminuria ranges between $4.8 \%$ and $10.3 \%$ [52], which significantly increases in high-risk populations such as patients with T2DM or hypertension.

The causative pathophysiological link between albuminuria and CV damage has been already described. Several studies have demonstrated a strong and linear association between albuminuria (even if moderately increased) and CV events in the general population [47,48], and in high-risk populations [53,54]. In addition, the communitybased Framingham Heart Study (FHS) reported an association between the presence of abnormal albuminuria and a higher risk of incident heart failure (HF) (HR 1.71, 95\% CI 1.25-2.34). In particular, albuminuria is associated with HF with reduced ejection fraction (HR 2.10, 95\% CI 1.35-3.26) but not in the forms with preserved ejection fraction (HR 1.26, 95\% CI 0.78-2.03) [55]. In the Multi-Ethnic Study of Atherosclerosis (MESA) study, diabetic subjects with albuminuria (micro- and macroalbuminuria combined) were $90 \%$ more likely to develop peripheral artery disease $(1.90,1.19-3.04)$ than those with no albuminuria [56]. For nondiabetic subjects, there were no statistically significant associations between albuminuria and vasculopathy [56]. However, the two studies, despite the large sample sizes, are either observational or cross-sectional, thus rendering it challenging to establish a causal effect of microalbuminuria and to generalize the results. Post-hoc analysis of the SAVOR-TIMI 53 trial in diabetic patients also identified an increased CV risk among patients with microalbuminuria, even if this was obtained just once, at the beginning of the trial [57]. In diabetic patients, even with a small increase in albuminuria (range 10-29 mg/g), the adjusted risk of cardiovascular death (aHR 1.65, 95\% CI 1.24-2.21), ischemic stroke (aHR 1.43, 95\% CI 1.02-2.01), myocardial infarction (aHR 1.73, 95\% CI 1.33-2.24) and hospitalization for heart failure (aHR 1.65, 95\% CI 1.22-2.21) was significantly higher [57]. Finally, in patients with overt diabetic nephropathy, the presence of albuminuria represents the most important factor predicting cardiovascular risk [54]. Patients with baseline albuminuria $\geq 3 \mathrm{~g} / \mathrm{g}$ creatinine had a 92\% higher risk (aHR 1.92, 95\% CI 1.54-2.38) for the cardiovascular end point and a 2.70-fold (95\% CI, 1.94 to 3.75) higher risk for HF compared with patients with low albuminuria ( $<1.5 \mathrm{~g} / \mathrm{g}$ creatinine). Interestingly, modeling of the initial 6-month change in risk parameters showed that albuminuria reduction by $50 \%$ was the only predictor for cardiovascular outcome associated with an $18 \%$ and $27 \%$ reduction in CV risk and heart failure, respectively [58]. In a cohort of 742 T2DM patients with diabetic nephropathy, the risk of adverse CV events increased from $19 \%$ to $40 \%$ as estimated glomerular filtration rate (eGFR) declined from the CKD stage 1 to the stage $3 b-5$ and by $25 \%$ and $33 \%$ in micro- and macroalbuminuria, respectively [6]. Of note, this study reported a significant interaction between albuminuria and eGFR $(p=0.01)$, thus suggesting that albuminuria had a remarkable prognostic effect in subjects with high eGFR, virtually disappearing as eGFR became $<30 \mathrm{~mL} / \mathrm{min} / 1.73 \mathrm{~m}^{2}$ [6].

Moreover, an increased albuminuria promotes higher tubular albumin reabsorption, with consequent intra-renal trafficking, which in turn activates the release of several inflammatory and pro-fibrotic mediators accelerating renal damage [59]. These mechanisms explain why albuminuria is now considered the principal risk factor predicting the faster progression of renal disease towards end-stage kidney disease (ESKD) [60-64].

Albuminuria acts as the main pathogenetic factor similarly in both diabetic and nondiabetic patients. Recently, a large multicentre observational study performed a direct 
comparison between CKD patients with the same proteinuria level either with or without T2DM [58]. Authors assessed the occurrence of different outcomes, including ESKD, in patients stratified by the presence of T2DM and proteinuria level $(<0.15,0.15-0.49,0.5-1$ and $>1 \mathrm{~g} /$ day). They found that adjusted risk (aHR) for ESKD progressively increased across proteinuria strata and became significant with proteinuria in the range $0.5-1$ (aHR 1.80 and 1.85, in diabetic and non-diabetic patients, respectively) and $>1 \mathrm{~g} /$ day (aHR 2.70 and 2.69, in diabetic and non-diabetic patients, respectively), thus underlying a major and independent role of proteinuria [65]. However, although all patients received reninangiotensin system (RAS) inhibitors at the maximally tolerated dose, no information of changes over time of proteinuria was available. Furthermore, albuminuria has an intrinsic pathophysiological limitation, being dependent not only on the extent of renal damage but also on the number and function of residual nephrons. Consequently, a low albuminuria level can herald a better prognosis in patients responding to antialbuminuric treatment or, alternatively, be merely a consequence of low eGFR. In the latter case, albuminuria alone may lose its prognostic significance likely because metabolic and hemodynamic factors associated with low eGFR play a major role in renal risk stratification. In this regard, the use of albuminuria (or proteinuria) indexed to eGFR as a more sensitive biomarker for the prediction of ESKD risk in a large cohort of CKD patients has been recently proposed [66]. This biomarker would allow an improvement in risk classification in more than $12 \%$ of patients, with higher reclassification in the elderly and in T2DM and advanced CKD, as well as in renal diseases characterized by higher proteinuria (diabetic nephropathy and glomerulonephritis) [66].

In recent years, there has been a growing interest in using change in albuminuria as a potential surrogate marker of CKD onset and progression rather than the single albuminuria level $[60,67,68]$. Sumida et al. reported, in a nationwide cohort of about 57,000 veterans (91\% diabetics) with an eGFR $\geq 60 \mathrm{~mL} / \mathrm{min}$, a nearly linear association between 1-year changes in albuminuria and incident CKD. The aHR of incident CKD associated with mild albuminuria increase (1.25-2 times), and severe albuminuria increase (>2 times) were 1.12 (95\% CI, 1.05-1.20) and 1.29 (95\% CI, 1.21-1.38), respectively [68]. Moreover, Carrero et al. showed in a cohort of about 20,000 participants (61\% diabetics) a strong association between change in albumin creatinine ratio (ACR) and the risk of ESKD [60]. The hazard of starting dialysis over a 2-year period was almost linear and did not differ according to diabetic status [60]. In contrast, several meta-analyses on data from clinical trials reported controversial results on the strength of associations between change in albuminuria and risk of ESKD $[60,61]$. However, their findings were weakened by the inclusion of highly selected populations, small sample sizes, and relatively short followup. Conversely, a recent individual participant-level meta-analysis of 28 observational studies including almost 700,000 subjects $(80 \%$ with $\mathrm{T} 2 \mathrm{DM})$ provided robust results on the association between albuminuria change and subsequent risk of ESKD, with reliable estimates across a wide range of cohorts and subgroups [69-71]. This meta-analysis testified that a decrease of $30 \%$ in ACR during a baseline period of 2 years was associated with a $22 \%$ reduction in risk of ESKD, also accounting for regression dilution (HR 0.78, 95\% CI 0.66-0.92). The lower risk of ESKD was consistent when albuminuria was quantified using UACR instead of albuminuria, when albuminuria changes were assessed at different time points (over 1 or 3 years) and when patients were stratified by the use of RAS inhibitors [71]. These analyses substantially improve the understanding of quantitative associations between the early change in albuminuria and the clinical endpoint of ESKD, and their application as a surrogate endpoint to groups of individuals in clinical trials. Mean change in albuminuria as an endpoint in clinical trials overcomes the inaccuracy of its estimation at the individual level, which results from substantial biological variation and laboratory measurement error. In particular, when corrected for regression dilution (regression to the mean effect), even modest changes in the true albuminuria level are reliably associated with meaningful changes in subsequent risk of ESKD. ADVANCE-ON, an extended 5 year follow-up of a diabetes clinical trial, is the only other study to adjust for 
regression dilution, obtaining similar findings in a population characterized by different ethnic groups [72]. All these results suggest, in the case of high baseline albuminuria, an association of a significant reduction in the risk of ESKD with even moderate true changes in albuminuria, rather than with imprecise single measure changes (e.g., 30\% decrease).

\section{Intervention Studies about the Reduction in Albuminuria and Risk of Kidney Outcome}

Observational studies can only testify an association between albuminuria and ESKD but cannot prove a cause-effect relationship. The critical question of whether a druginduced reduction in albuminuria value can predict renal protection may be answered only by examining randomized clinical trials (RCTs) and trial-based meta-analyses (Table 1).

Lambers-Heerspink et al. evaluated early albuminuria reduction in response to various pharmacological interventions as a predictor of the treatment effect on ESKD. The authors considered twenty-one RCTs, of which seven included only DKD patients [69]. As the main result, they observed a $24 \%$ ESKD risk reduction $(95 \%$ CI, 11-34) for each 30\% reduction in albuminuria. This association was consistent regardless of drug class $(p=0.73)$ and diabetic status $(p=0.89)$. However, the association between early changes in albuminuria and kidney events in this study is primarily based on trials of renin-angiotensin system blockade. Therapy with RAS inhibitors remains the main reno-protective intervention in DKD, although $30 \%$ to $50 \%$ of patients still present a high residual risk of ESKD [73]. More recently, a further meta-analysis of 41 RCTs with about 30,000 participants (71\% with T2DM) has evaluated the relationship between treatment effects on albuminuria and renal endpoint by using a Bayesian mixed-effects meta-regression analysis [74] Across all studies, therapeutic strategies reducing by at least $30 \%$ the geometric mean albuminuria as compared to control are associated with a $27 \%$ lower risk of composite renal endpoint (ESKD, eGFR $<15 \mathrm{~mL} / \mathrm{min} / 1.73 \mathrm{~m}^{2}$, or doubling of serum creatinine), with a meta-regression slope of 0.89 (95\% Bayesian credible interval 0.13-1.70) [74]. The association was stronger in patients with baseline albuminuria $>30 \mathrm{mg} / \mathrm{g}$ but weaker for patients with low baseline levels of albuminuria [74].

In the last few years, the introduction in the therapeutic armamentarium of Sodium Glucose Transporter-2 inhibitors (SGLT2-i) has dramatically modified the renal risk of T2DM patients, mainly due to the hemodynamic and anti-albuminuric properties of these drugs. The beneficial renal effects of SGLT2-i were initially shown in the cardiovascular outcome trials EMPAREG, CANVAS and DECLARE, aimed at evaluating cardiovascular safety in T2DM patients, in which renal outcomes were assessed as secondary endpoints [75-77]. Besides these, the CREDENCE trial specifically aimed to evaluate the renal survival in a large population with T2DM with overt CKD receiving either Canagliflozin or placebo [78]. Overall, the results of these four large RCTs demonstrated, along with cardiovascular benefits [79,80], a major nephroprotective efficacy of SGLT2-i, with a significant 30\% reduction in albuminuria and a 30-40\% lower risk of progression to ESKD [66-69]. A recent post hoc analysis of the CREDENCE trial further investigated whether an early change in albuminuria after treatment with Canagliflozin is associated with long-term kidney outcomes [81]. Overall, Canagliflozin, as compared to placebo, reduced geometric mean ACR at 26 weeks by $31 \%$ (95\% CI, 27\% to 36\%). Over a median follow-up of 2.2 years, 324 $(8.4 \%)$ kidney outcomes were observed. This study demonstrated that each $30 \%$ decrease in albuminuria during the first months of treatment with Canagliflozin was associated with a $29 \%$ reduced risk of kidney outcomes in DKD patients (HR, 0.71; 95\% CI, 0.67-0.76) [72]. Furthermore, despite early and sustained reductions in albuminuria with Canagliflozin, the authors observed residual albuminuria, which was associated with kidney and cardiovascular events both in placebo and Canagliflozin groups. This displays the importance of monitoring albuminuria during Canagliflozin treatment to better target both renal and CV prognosis.

The CREDENCE demonstrated a stronger association between change in albuminuria and kidney outcomes rather than for CV outcomes, underlying the central role of albuminuria as a risk factor for kidney events, whereas CV risk is determined by multiple other 
factors, including hyperglycemia and hyperlipidemia. The reduction of the renal endpoint was larger for higher baseline levels of albuminuria. Nevertheless, the reductions in albuminuria might explain around $50 \%$ of the treatment effect on the primary kidney outcome. This finding is consistent with recent data from the CANVAS Program [82]. However, it should be kept in mind that Canagliflozin, as well as the other SGLT2i, cannot be used in patients either with a low eGFR or in dialysis. Hence, the effects on these patients are unknown. In addition, as pointed out by the authors, there are few albuminuric patients. On the other hand, indeed, a beneficial effect of gliflozins also in normoalbuminuric patients should be mentioned, which suggests the involvement of other drug-related mechanisms in kidney protection.

Renal-protective effects associated with a significant reduction in albuminuria values were further observed with another class of drugs, selective antagonists of endothelin A receptor (ETA-RA). In particular, the SONAR trial found an ACR reduction from baseline of $51.8 \%$ (95\% CI, 51.4-52.4) in about 2700 albuminuric T2DM patients with reduced eGFR responding to Atrasentan in the enrichment period [83]. This reduction was further associated with a lower risk of primary composite renal endpoint (sustained doubling of serum creatinine, eGFR $<15 \mathrm{~mL} / \mathrm{min} / 1.73 \mathrm{~m}^{2}$, chronic dialysis, kidney transplantation, or death from kidney failure) in subjects treated with Atrasentan (HR: 0.65 (95\% CI 0.49-0.88)) after a median follow-up of 2.2 years [83]. A more recent post hoc analysis of the SONAR trial was focused on a small subgroup $(n=14)$ of patients treated with a combination of SGLT2-i and Atrasentan during the 6-week active open-label (enrichment) period [84]. These 14 patients were matched (1:3 ratio) with patients under Atrasentan monotherapy. Dual administration of SGLT2-i and Atrasentan was associated with a $28 \%$ (95\% CI, 4-46\%) larger reduction in ACR as compared to Atrasentan alone, hence suggesting a beneficial synergistic effect from the combined therapy resulting in a higher albuminuria reduction and renoprotection. These promising findings support future RCTs designed to assess the long-term efficacy and safety of a combined therapy with ETA-RA and SGLT2-i in high-risk patients with T2DM and CKD [84].

Finally, new interesting insights in the renoprotective strategies arise from the Finerenone in Reducing Kidney Failure and Disease Progression in Diabetic Kidney Disease (FIDELIODKD) trial [85]. This study was designed to test the hypothesis that Finerenone, a nonsteroidal selective mineralocorticoid receptor antagonist, slows the progression of kidney disease and reduces both CV morbidity and mortality among DKD patients. As compared to placebo, Finerenone was associated with a $31 \%$ greater reduction of ACR during the first 4 months of the trial, which persisted in the following 30 months. More importantly, Finerenone also reduced the incidence of the primary composite kidney outcome (defined as kidney failure, sustained decrease of at least $40 \%$ in the eGFR from baseline or death from renal causes) by $18 \%$ (HR: $0.82 ; 95 \%$ CI, $0.73-0.93$ ). Notably, the renoprotective effect of Finerenone was mainly driven by the sustained eGFR decline $\geq 40 \%$ (HR 0.81 (95\% CI 0.72-0.92)), which is a validated surrogate endpoint of renal progression [86]. Hyperkalemia-related adverse events occurred more frequently with Finerenone than with placebo ( $18 \%$ and $9.0 \%$, respectively), which was expected, also considering that $>50 \%$ of T2DM enrolled patients had eGFR $<45 \mathrm{~mL} / \mathrm{min} / 1.73 \mathrm{~m}^{2}$. However, the discontinuation rate due to hyperkalaemia was only $2.3 \%$. The benefit with respect to CKD progression was lower than that reported with Canagliflozin in the CREDENCE trial, more likely because SGLT2-i were allowed in the FIDELIO-DKD, thus leading to a higher renoprotection in the placebo group, whereas patients treated with mineralocorticoid receptor antagonists were excluded from the CREDENCE trial [78]. 
Table 1. Findings from the randomized clinical trials on cardiorenal outcome with antihypertensive and anti-hyperglycaemic drugs

\begin{tabular}{|c|c|c|c|c|c|c|c|c|c|c|}
\hline RCT & $\begin{array}{l}\text { Publication } \\
\text { Date }\end{array}$ & $\begin{array}{l}\text { Active Drug/ } \\
\text { Comparator }\end{array}$ & $\begin{array}{c}\text { No. } \\
\text { Patients }\end{array}$ & $\begin{array}{l}\text { Median } \\
\text { Follow-Up } \\
\text { (yrs.) }\end{array}$ & $\begin{array}{c}\text { Baseline eGFR } \\
\left(\mathrm{mL} / \mathrm{min} / \mathrm{m}^{2}\right)\end{array}$ & $\begin{array}{l}\text { Baseline } \\
\text { Albuminuria }\end{array}$ & $\begin{array}{c}\text { Risk of } \\
\text { Composite } \\
\text { CV Endpoint }\end{array}$ & $\begin{array}{l}\text { Risk of } \\
\text { CV Death }\end{array}$ & $\begin{array}{c}\text { Risk of } \\
\text { Composite } \\
\text { Renal Outcome }\end{array}$ & $\begin{array}{c}\text { Reduced } \\
\text { Proteinuria }\end{array}$ \\
\hline $\begin{array}{c}\text { HOPE/MICRO- } \\
\text { HOPE } \\
\text { [83] }\end{array}$ & 2000 & $\begin{array}{l}\text { Ramipril } \\
\text { vs. Placebo }\end{array}$ & 3577 & 4.5 & n.a. & $553 \mathrm{mg} / \mathrm{g}$ & $-25 \%$ & $-37 \%$ & $-16 \%$ & $9 \%$ \\
\hline $\begin{array}{c}\text { RENAAL } \\
{[59,85]}\end{array}$ & 2001 & $\begin{array}{c}\text { Losartan } \\
\text { vs. Placebo }\end{array}$ & 1513 & 3.4 & 39.5 & $1168 \mathrm{mg} / \mathrm{g}$ & $-10 \%$ & $-2 \%$ & $-16 \%$ & $-35 \%$ \\
\hline $\begin{array}{c}\text { DIABHYCAR } \\
{[84]}\end{array}$ & 2004 & $\begin{array}{c}\text { Ramipril } \\
\text { vs. Placebo }\end{array}$ & 4912 & 4 & n.a. & $65 \mathrm{mg} / \mathrm{L}$ & $-3 \%$ & $3 \%$ & $-7 \%$ & $-19 \%$ \\
\hline $\begin{array}{c}\text { SUSTAIN-6 } \\
\text { [87] }\end{array}$ & 2016 & $\begin{array}{l}\text { Semaglutide } \\
\text { vs. Placebo }\end{array}$ & 3297 & 2.1 & 76.1 & $38.6 \mathrm{mg} / \mathrm{g}$ & $-26 \%$ & $-2 \%$ & n.a. & n.a. \\
\hline $\begin{array}{c}\text { EMPA-REG } \\
{[71,88]}\end{array}$ & 2017 & $\begin{array}{c}\text { Empagliflozin } \\
\text { vs. Placebo }\end{array}$ & 7020 & 3.1 & 74.2 & $25.51 \mathrm{mg} / \mathrm{L}$ & $-14 \%$ & $-38 \%$ & $-46 \%$ & n.a. \\
\hline $\begin{array}{l}\text { CANVAS } \\
{[72,78,89]}\end{array}$ & 2017 & $\begin{array}{c}\text { Canagliflozin } \\
\text { vs. Placebo }\end{array}$ & 10,142 & 2.4 & 76.7 & $12.3 \mathrm{mg} / \mathrm{g}$ & $-14 \%$ & $-13 \%$ & $-40 \%$ & $-27 \%$ \\
\hline $\begin{array}{c}\text { ADVANCE-ON } \\
\text { [68] }\end{array}$ & 2018 & $\begin{array}{l}\text { Perindopril/ } \\
\text { Indapamide vs. } \\
\text { Placebo }\end{array}$ & 8766 & 7.7 & n.a. & $48.7 \mathrm{mg} / \mathrm{g}$ & $-16 \%$ & $-19 \%$ & $-37 \%$ & n.a. \\
\hline $\begin{array}{l}\text { DECLARE- } \\
\text { TIMI58 } \\
{[73,90]} \\
\end{array}$ & 2019 & $\begin{array}{l}\text { Dapagliflozin } \\
\text { vs. Placebo }\end{array}$ & 17,160 & 4.2 & 85.4 & n.a. & $-7 \%$ & $-2 \%$ & $-47 \%$ & n.a. \\
\hline DAPA-HF [91] & 2019 & $\begin{array}{c}\text { Dapagliflozin } \\
\text { vs. Placebo }\end{array}$ & 4744 & 1.52 & 66 & n.a. & n.a. & $-18 \%$ & $-29 \%$ & n.a. \\
\hline REWIND [92] & 2019 & $\begin{array}{l}\text { Dulaglutide } \\
\text { vs. Placebo }\end{array}$ & 9901 & 5.4 & 77.2 & $15.93 \mathrm{mg} / \mathrm{g}$ & $-12 \%$ & $-\%$ & $-15 \%$ & $-23 \%$ \\
\hline SONAR $[79,80]$ & 2019 & $\begin{array}{l}\text { Atrasentan } \\
\text { vs. Placebo }\end{array}$ & 11,087 & 2.2 & 44 & $797 \mathrm{mg} / \mathrm{g}$ & $-12 \%$ & $10 \%$ & $-35 \%$ & $39 \%$ \\
\hline $\begin{array}{l}\text { FIDELIO-DKD } \\
\text { [81] }\end{array}$ & 2020 & $\begin{array}{l}\text { Finerenone } \\
\text { vs. Placebo }\end{array}$ & 5734 & 2.6 & 44.4 & $833 \mathrm{mg} / \mathrm{g}$ & $-14 \%$ & $-14 \%$ & $-18 \%$ & $-19 \%$ \\
\hline
\end{tabular}


In conclusion, all the renoprotective new drugs currently available act producing an early and sustained reduction in albuminuria. This effect translates in the long-term in a significant reduction in renal events. Change in albuminuria is a biologically reasonable surrogate endpoint for the progression of CKD in RCTs, and clinicians must consider the early decrease in albuminuria as a reliable biomarker of a favorable response to treatment. Whether SGLT2-1, ETA-RA and mineralocorticoid receptor antagonists exert a significant impact in reducing renal events and also in the non-albuminuric phenotype of T2DM patients still remains to be verified by dedicated studies.

\section{Non-Pharmacological Approach for Proteinuria Reduction}

Besides pharmacological treatment, some non-pharmacological strategies have been proposed to reduce albuminuria in both diabetic and non-diabetic patients with $C K D$. The most common approaches include reduction of protein intake and low sodium diet [93]. Experimental models have demonstrated a large efficacy of a low protein diet (LPD) in reducing glomerular hyperfiltration by inducing vasoconstriction of afferent arterioles, with a subsequent decrease in the intraglomerular pressure. In this way, LDP pre-glomerular effects can act synergistically with the post-glomerular effects of RAS-inhibitors (efferent vasodilation). In addition, improvement in glomerular hyperfiltration may reduce renal inflammation by limiting the release of both pro-inflammatory and pro-fibrotic cytokines from the mesangial cells [94]. A very recent meta-analysis has reported a significant reduction of proteinuria and a slower decline over time of eGFR in DKD patients following a daily protein intake limited to less than $0.8 \mathrm{~g} / \mathrm{kg} /$ day [95]. These data were consistent with other meta-analyses, although these latter included a lower number of studies and subjects [87,92,96]. LPD benefits may also include improvements in lipid and glucose control, especially in subjects at an early stage of kidney disease [95]. Among low-protein diets for $\mathrm{CKD}$, there is a very restrictive one, which is supplemented with aminoacids and ketoacids (LPD-KA) in order to cover the minimum body nitrogen need and to minimize the nitrogen load. The LPD-KA diet has been proven to achieve a more effective metabolic control, a reduction of CV risk factors and also a slow-down of CKD progression by delaying the need for dialysis $[88,89]$. On the other hand, a very restricted renal diet may expose the patient with CKD to a higher risk of insufficient nutrient intake and protein-energy wasting, particularly in diabetic patients, in which the higher degree of inflammation, insulin resistance and more frequent hyper-catabolism might require more proteins and aminoacids to compensate the catabolic status. In a recent observational study, Bellizzi et al. reassured clinicians on the long-term effects of LPD-KA in diabetic CKD patients by testifying that a low-protein diet supplemented with ketoacids improves the accumulation of uremic products and ameliorates both glucose control and insulin sensitivity [90]. This dietary strategy did not worsen the nutritional status while preserving the body composition in diabetic patients with CKD.

Despite the encouraging results and the evident pathophysiological link between protein intake and proteinuria, further randomized trials are needed to confirm the usefulness of LPD as renoprotective strategy. Indeed, the most recent nutritional guidelines indicate as reasonable the prescription of a dietary protein intake between 0.6 and $0.8 \mathrm{~g} / \mathrm{kg} / \mathrm{day}$ in diabetic kidney disease patients to maintain a stable nutritional status and optimize glycemic control [91]. Despite this statement only being an opinion, being supported by too low-quality evidence to produce a graded recommendation, it is of utmost importance to provide some guidance both to patients and practitioners.

Notably, LPD can be synergistic with the direct effect of a low-sodium diet [93]. In all adults with CKD $[87,95,96]$, it is recommended to limit sodium intake $<100 \mathrm{mmol} /$ day to reduce blood pressure and proteinuria [91]. In the short term both observational and randomized studies, sodium restriction is effective in correcting the volume overload occurring since the early stages of CKD and, consequently, reduces blood pressure (BP) and proteinuria [97-100]. Similarly, in a pooled analysis of IDNT and RENAAL trials in patients with diabetic nephropathy, the beneficial effect of RAS inhibitors on both renal 
and cardiovascular outcomes is higher in patients following a low-salt diet (LSD) [101]. Recently, in a meta-analysis of 11 RCTs including 738 CKD patients (Stage 1-4, 46\% with T2DM), LSD was associated with a significant decline of clinical and $24 \mathrm{~h}$ outpatient BP, as well as of proteinuria $(-0.4 \mathrm{~g} /$ day, $95 \% \mathrm{CI}$ from -0.55 to $-0.22, p<0.001)$ [102]. Changes in proteinuria display a linear correlation with changes in systolic BP, suggesting that the anti-proteinuric effect of sodium restriction may be dependent on BP reduction. On the other hand, it cannot be ruled out that LSD may exert its anti-proteinuric effect by enhancing the efficacy of drugs inhibiting RAS. Indeed, in a small randomized cross-over trial on 52 non-diabetic CKD patients, LSD enhanced the anti-proteinuric effect of lisinopril by obtaining a proteinuria reduction (51\%) even higher than that detected after dual RAS blockade (21\% after lisinopril and valsartan combination) [98]. When considering that both CKD and diabetes are characterized by a "salt-sensitive" phenotype, one would expect that favorable effects obtained in non-diabetic patients might be extended to the entire diabetic population.

\section{Proteinuria Reduction and Cardiovascular Prevention in T2DM: RCTs-Based Evidence}

Significant evidence has shown how altered levels of proteinuria and micro/ macroalbuminuria are suggestive not only of renal damage, but also of cardiovascular diseases [6]. In addition, they may also represent a negative prognostic factor for the worsening of both renal and cardiac disorders [65]. For this reason, several trials related to both anti-proteinuric and anti-hyperglycemic drugs have assessed whether proteinuria reduction could positively affect cardiovascular outcomes (Figure 2).

Before the marketing of the new anti-hyperglycemic drugs-Dipeptidyl peptidase 4 inhibitors (DPP-4i), Sodium Glucose Cotransporter2 inhibitors (SGLT2i) and glucagon-like peptide 1 (GLP1ra) — the only drugs reported as effective towards high levels of proteinuria, with subsequent renal and cardiovascular protection, were Angiotensin-converting enzyme inhibitors (ACE-i) and angiotensin receptor blockers (ARBs).

MICRO-HOPE findings are very promising. The authors have assessed both renal and cardiovascular outcomes in a subpopulation from the HOPE trial, characterized by type 2 diabetes and microalbuminuria. ACEi has been reported to reduce both single and composite cardiovascular outcomes, with a subsequent reduction of up to the $16 \%$ of renal damage progression [103]. Conversely, in the DIABHYCAR study, a low dosage of Ramipril (1.25 mg/die) in about 5000 T2DM patients with persistent proteinuria did not prove effective in reducing the composite cardiovascular outcome despite a remarkable improvement of renal markers [104]. These differences in results could depend on the different study designs of these trials in terms of enrollment criteria and ACEi dosage. This latter point could suggest a dose-dependent effect of the ACEi, with a maximal benefit from higher dosages.

Likewise, ARBs have demonstrated a protective role in both renal and cardiovascular protection. Most studies have particularly focused on cardiovascular outcomes in T2DM patients with kidney dysfunction. The RENAAL study, which involved about 5000 patients with diabetes and nephropathy, reported losartan's effectiveness on cardiovascular outcomes by reducing microalbuminuria [58]. In fact, the authors found that microalbuminuria was the main marker of cardiovascular damage, particularly in the presence of an anti-proteinuric effect $>30 \%$. However, the physiopathological mechanisms are still unclear.

In contrast to the previous studies, losartan, despite reducing proteinuria, does not seem to exert a protective CV effect [105]. In particular, a recent study reported that both monotherapy and ACE/ARBs combination do not increase renal and cardiovascular efficacy [106]. As reported by other authors, indeed, ACEi effectiveness on cardiovascular protection might be due to a decrease of lipoproteins, with a consequent reduction of the atheromatic plaque [107]. However, this latter seems characterized by several limitations, particularly a low sample size and the absence of a placebo control group. As such, the 
authors suggested the need for large-scale trials and studies with a longer follow-up to better assess this topic.

The relationship between either altered renal function or proteinuria/microalbuminuria and cardiovascular outcome in diabetic patients has also been assessed in relation to antihyperglycemic therapeutic regimens.

As expected, the post-hoc analysis of SAVOR-TIMI has shown a correlation between renal function/microalbuminuria and cardiovascular outcome [108]. However, Saxagliptin did not prove effective with respect to placebo, neither on the renal outcome nor on the cardiovascular, regardless of eGFR and kidney failure [57]. The TECOS study, which assessed sitagliptin efficacy on almost 15,000 patients, did not report a higher renal benefit as compared to placebo after a 4 year follow-up. However, the authors conducted the analyses stratifying only for eGFR, regardless of microalbuminuria and proteinuria assessment [109]. Alogliptin, indeed, up to now has never been tested for its relationship with renal function markers.

Among GLP-1ra, the LEADER study revealed a higher efficacy of Liraglutide with respect to placebo versus all MACEs and single cardiovascular outcomes in a population at high CV risk and eGFR $<60 \mathrm{~mL} / \mathrm{min}$, regardless of baseline microalbuminuria [110].

In the SUSTAIN 1-7, which assessed the effects of Semaglutide as compared to both placebo and other competitors, the drug showed significant protection on the cardiovascular outcome. In SUSTAIN 1-5 and 7, this effect was accompanied by an overall reduction in eGFR, whilst in SUSTAIN 6, no difference was observed. In addition, the albuminuria-lowering effects were higher in patients with either microalbuminuria or macro albuminuria in the semaglutide or active-comparator treatment groups, while no effect was observed in the normo-albuminuria group [111]. These findings are likely limited by a short follow-up.

More recently, the REWIND study, which compared Dulaglutide with placebo in patients at high cardiovascular risk, reported a reduction at 5-years of the risk of macroalbuminuria development of $23 \%$ (HR 0.77, 95\% CI 0.68-0.87; $p<0.0001$ ). The authors suggest that this behavior, in relation to the findings, may also be extended to the cardiovascular outcome, due to the effects of the drug on both blood pressure and endothelial damage [112].

Among SGLT2i, a post-hoc analysis from the EMPAREG-Outcome reported a $18 \%$ reduction in urinary albumin creatinine ratio (UACR) with Empagliflozin as compared to placebo and an increased likelihood of a UACR decrease $>30 \%$. This reduction in the short term also was significantly associated with a lower risk of both cardiovascular and renal outcomes in the long term [113].

Consistently with the EMPAREG Outcome findings, in the CANVAS clinical trial, Canagliflozin displayed significant non-inferiority and superiority of the composite cardiovascular outcome (death from cardiovascular causes, nonfatal myocardial infarction, or nonfatal stroke) with a risk reduction (RR) of $14 \%$ (HR 0.86, 95\% CI 0.75-0.97; $p<0.001$ and $p=0.002$, respectively) compared to placebo, although no difference was observed on the single outcomes. In parallel, Canagliflozin also positively affected both the progression of albuminuria (HR 0.73, 95\% CI 0.67-0.79) in those with a baseline normo/micro/ macroalbuminuria profile and its regression (HR 1.70, 95\% CI 1.51 to 1.91) [114]. This topic has been further assessed in the DECLARE-TIMI 58. In particular, the authors observed, in a population of about 17,000 patients, non-inferiority of Dapagliflozin as compared to placebo regarding the risk of MACE, despite a non-significant rate reduction of MACE. However, the significantly lower rate of $\mathrm{CV}$ death and hospitalization for HF in different sub-groups allows us to suppose an overall cardiovascular benefit [115]. Consistently with the CV outcome, DECLARE authors, as already previously reported by Petrykiv et al., further reported an improvement of renal function (in terms of eGFR and microalbuminuria reduction) associated with a concomitant improvement of CV outcome [116].

In conclusion, $\mathrm{ACEi}$ and $\mathrm{ARBs}$ largely demonstrated an anti-proteinuric and cardioprotective effect. Beyond them, in recent years, among anti-hyperglycemic drugs, GLP-1ra 
and SGLT2i have proven effective in reducing either the progression or the regression of microalbuminuria, thus resulting in a cardiovascular benefit also in patients with overt renal damage.

\section{Conclusions}

Albuminuria is a marker of renal damage and CV risk in diabetic subjects. Currently, albuminuria/proteinuria still represents an important prognostic factor for the onset and progression of both DKD and CVD. Several studies have demonstrated a beneficial effect of its reduction in both kidney and heart as exerted by new drugs. However, new RCTs are needed to confirm these exciting findings, especially with a longer follow-up.

Author Contributions: Conceptualization, F.C.S. and R.M.; investigation, R.G., P.C.P., C.G., S.B., A.C., M.P., L.R., T.S. and L.D.N.; writing-original draft preparation, R.G., P.C.P., C.G., R.M. and F.C.S.; writing-review and editing, R.G., P.C.P., C.G., R.M. and F.C.S.; supervision, L.D.N. and T.S. All authors have read and agreed to the published version of the manuscript.

Funding: This research received no external funding.

Institutional Review Board Statement: Not applicable.

Informed Consent Statement: Not applicable.

Conflicts of Interest: The authors declare no conflict of interest.

\section{References}

1. Mogensen, C.E. Microalbuminuria Predicts Clinical Proteinuria and Early Mortality in Maturity-Onset Diabetes. N. Engl. J. Med. 1984, 310, 356-360. [CrossRef] [PubMed]

2. Rosansky, S.J.; Schell, J.; Shega, J.; Scherer, J.; Jacobs, L.; Couchoud, C.; Crews, D.; McNabney, M. Treatment decisions for older adults with advanced chronic kidney disease. BMC Nephrol. 2017, 18, 200. [CrossRef] [PubMed]

3. Esposito, G.; Testa, F.; Zacchia, M.; Crispo, A.A.; Di Iorio, V.; Capolongo, G.; Rinaldi, L.; D’ Antonio, M.; Fioretti, T.; Iadicicco, P.; et al. Genetic characterization of Italian patients with Bardet-Biedl syndrome and correlation to ocular, renal and audio-vestibular phenotype: Identification of eleven novel pathogenic sequence variants. BMC Med. Genet. 2017, 18, 1-12. [CrossRef]

4. Giordano, M.; Ciarambino, T.; Castellino, P.; Malatino, L.; Cataliotti, A.; Rinaldi, L.; Paolisso, G.; Adinolfi, L.E. Seasonal variations of hyponatremia in the emergency department: Age-related changes. Am. J. Emerg. Med. 2017, 35, 749-752. [CrossRef]

5. Norris, K.C.; Smoyer, K.E.; Rolland, C.; Van Der Vaart, J.; Grubb, E.B. Albuminuria, serum creatinine, and estimated glomerular filtration rate as predictors of cardio-renal outcomes in patients with type 2 diabetes mellitus and kidney disease: A systematic literature review. BMC Nephrol. 2018, 19, 1-13. [CrossRef] [PubMed]

6. Sasso, F.C.; Chiodini, P.; Carbonara, O.; De Nicola, L.; Conte, G.; Salvatore, T.; Nasti, R.; Marfella, R.; Gallo, C.; Signoriello, S.; et al. High cardiovascular risk in patients with Type 2 diabetic nephropathy: The predictive role of albuminuria and glomerular filtration rate. The NID-2 Prospective Cohort Study. Nephrol. Dial. Transplant. 2011, 27, 2269-2274. [CrossRef]

7. Marfella, R.; Amico, M.D.; Di Filippo, C.; Siniscalchi, M.; Sasso, F.C.; Ferraraccio, F.; Rossi, F.; Paolisso, G. The possible role of the ubiquitin proteasome system in the development of atherosclerosis in diabetes. Cardiovasc. Diabetol. 2007, 6, 35. [CrossRef] [PubMed]

8. Torella, D.; Ellison, G.M.; Torella, M.; Vicinanza, C.; Aquila, I.; Iaconetti, C.; Scalise, M.; Marino, F.; Henning, B.J.; Lewis, F.C.; et al. Carbonic Anhydrase Activation Is Associated With Worsened Pathological Remodeling in Human Ischemic Diabetic Cardiomyopathy. J. Am. Heart Assoc. 2014, 3, e000434. [CrossRef] [PubMed]

9. Marfella, R.; Ferraraccio, F.; Rizzo, M.R.; Portoghese, M.; Barbieri, M.; Basilio, C.; Nersita, R.; Siniscalchi, L.I.; Sasso, F.C.; Ambrosino, I.; et al. Innate Immune Activity in Plaque of Patients with Untreated andl-Thyroxine-Treated Subclinical Hypothyroidism. J. Clin. Endocrinol. Metab. 2011, 96, 1015-1020. [CrossRef]

10. Calabrò, P.; Moscarella, E.; Gragnano, F.; Cesaro, A.; Pafundi, P.C.; Patti, G.; Cavallari, I.; Antonucci, E.; Cirillo, P.; Pignatelli, P.; et al. Effect of Body Mass Index on Ischemic and Bleeding Events in Patients Presenting With Acute Coronary Syndromes (from the START-ANTIPLATELET Registry). Am. J. Cardiol. 2019, 124, 1662-1668. [CrossRef]

11. Sasso, F.C.; Pafundi, P.C.; Gelso, A.; Bono, V.; Costagliola, C.; Marfella, R.; Sardu, C.; Rinaldi, L.; Galiero, R.; Acierno, C.; et al. High HDL cholesterol: A risk factor for diabetic retinopathy? Findings from NO BLIND study. Diabetes Res. Clin. Pr. 2019, 150, 236-244. [CrossRef] [PubMed]

12. Minutolo, R.; Sasso, F.C.; Chiodini, P.; Cianciaruso, B.; Carbonara, O.; Zamboli, P.; Tirino, G.; Pota, A.; Torella, R.; Conte, G.; et al. Management of cardiovascular risk factors in advanced type 2 diabetic nephropathy: A comparative analysis in nephrology, diabetology and primary care settings. J. Hypertens. 2006, 24, 1655-1661. [CrossRef] 
13. Sasso, F.C.; Pafundi, P.C.; Gelso, A.; Bono, V.; Costagliola, C.; Marfella, R.; Sardu, C.; Rinaldi, L.; Galiero, R.; Acierno, C.; et al. Applicability of telemedicine in the screening of diabetic retinopathy (DR): The first multicentre study in Italy. The No Blind Study. Diabetes/Metabol. Res. Rev. 2018, 35, e3113. [CrossRef] [PubMed]

14. Sasso, F.C.; Pafundi, P.C.; Gelso, A.; Bono, V.; Costagliola, C.; Marfella, R.; Sardu, C.; Rinaldi, L.; Galiero, R.; Acierno, C.; et al. Relationship between albuminuric CKD and diabetic retinopathy in a real-world setting of type 2 diabetes: Findings from No blind study. Nutr. Metab. Cardiovasc. Dis. 2019, 29, 923-930. [CrossRef] [PubMed]

15. Sasso, F.C.; Rinaldi, L.; Lascar, N.; Marrone, A.; Pafundi, P.C.; Adinolfi, L.E.; Marfella, R. Role of Tight Glycemic Control during Acute Coronary Syndrome on CV Outcome in Type 2 Diabetes. J. Diabetes Res. 2018, 2018, 1-8. [CrossRef]

16. Sasso, F.C.; Pafundi, P.C.; Marfella, R.; Calabrò, P.; Piscione, F.; Furbatto, F.; Esposito, G.; Galiero, R.; Gragnano, F.; Rinaldi, L.; et al. Adiponectin and insulin resistance are related to restenosis and overall new PCI in subjects with normal glucose tolerance: The prospective AIRE Study. Cardiovasc. Diabetol. 2019, 18, 1-13. [CrossRef]

17. Jhund, P.S.; McMurray, J.J.; Chaturvedi, N.; Brunel, P.; Desai, A.S.; Finn, P.V.; Haffner, S.M.; Solomon, S.D.; Weinrauch, L.A.; Claggett, B.L.; et al. Mortality following a cardiovascular or renal event in patients with type 2 diabetes in the ALTITUDE trial. Eur. Heart J. 2015, 36, 2463-2469. [CrossRef]

18. Cosentino, F.; Grant, P.J.; Aboyans, V.; Bailey, C.J.; Ceriello, A.; Delgado, V.; Federici, M.; Filippatos, G.E.; Grobbee, D.; Hansen, T.B.; et al. 2019 ESC Guidelines on diabetes, pre-diabetes, and cardiovascular diseases developed in collaboration with the EASD. Eur. Heart J. 2019, 41, 255-323. [CrossRef] [PubMed]

19. Campion, C.G.; Sanchez-Ferras, O.; Batchu, S.N. Potential Role of Serum and Urinary Biomarkers in Diagnosis and Prognosis of Diabetic Nephropathy. Can. J. Kidney Health Dis. 2017, 4, 2054358117705371. [CrossRef]

20. Roumeliotis, S.; Mallamaci, F.; Zoccali, C. Endothelial Dysfunction in Chronic Kidney Disease, from Biology to Clinical Outcomes: A 2020 Update. J. Clin. Med. 2020, 9, 2359. [CrossRef] [PubMed]

21. Liakopoulos, V.; Roumeliotis, S.; Gorny, X.; Dounousi, E.; Mertens, P.R. Oxidative Stress in Hemodialysis Patients: A Review of the Literature. Oxid. Med. Cell. Longev. 2017, 2017, 1-22. [CrossRef] [PubMed]

22. Parving, H.-H.; Lewis, J.B.; Ravid, M.; Remuzzi, G.; Hunsicker, L.G. Prevalence and risk factors for microalbuminuria in a referred cohort of type II diabetic patients: A global perspective. Kidney Int. 2006, 69, 2057-2063. [CrossRef] [PubMed]

23. Kannel, W.B.; Stampfer, M.J.; Castelli, W.P.; Verter, J. The prognostic significance of proteinuria: The Framingham study. Am. Heart J. 1984, 108, 1347-1352. [CrossRef]

24. Remuzzi, G.; Bertani, T. Is glomerulosclerosis a consequence of altered glomerular permeability to macromolecules? Kidney Int 1990, 38, 384-394. [CrossRef] [PubMed]

25. Feldt-Rasmussen, B. Increased transcapillary escape rate of albumin in Type 1 (insulin-dependent) diabetic patients with microalbuminuria. Diabetologia 1986, 29, 282-286. [CrossRef]

26. Oomen, P.H.; Jager, J.; Hoogenberg, K.; Dullaart, R.P.; Reitsma, W.D.; Smit, A.J. Capillary permeability is increased in normo- and microalbuminuric Type 1 diabetic patients: Amelioration by ACE-inhibition. Eur. J. Clin. Investig. 1999, 29, 1035-1040. [CrossRef]

27. Penno, G.; Renal Insufficiency Cardiovascular Events (RIACE) Study Group; Solini, A.; Zoppini, G.; Fondelli, C.; Trevisan, R.; Vedovato, M.; Cavalot, F.; Gruden, G.; Lamacchia, O.; et al. Independent correlates of urinary albumin excretion within the normoalbuminuric range in patients with type 2 diabetes: The Renal Insufficiency And Cardiovascular Events (RIACE) Italian Multicentre Study. Acta Diabetol. 2015, 52, 971-981. [CrossRef]

28. Klimontov, V.V.; Korbut, A.I. Albuminuric and non-albuminuric patterns of chronic kidney disease in type 2 diabetes. Diabetes Metab. Syndr. Clin. Res. Rev. 2019, 13, 474-479. [CrossRef] [PubMed]

29. Gschwend, S.; Buikema, H.; Navis, G.; Henning, R.H.; De Zeeuw, D.; Van Dokkum, R.P.E. Endothelial dilatory function predicts individual susceptibility to renal damage in the 5/6 nephrectomized rat. J. Am. Soc. Nephrol. 2002, 13, 2909-2915. [CrossRef] [PubMed]

30. Ochodnicky, P.; Henning, R.H.; Buikema, H.; Kluppel, A.C.A.; Van Wattum, M.; De Zeeuw, D.; Van Dokkum, R.P.E. Renal endothelial function and blood flow predict the individual susceptibility to adriamycin-induced renal damage. Nephrol. Dial. Transplant. 2008, 24, 413-420. [CrossRef]

31. Verhave, J.C.; Hillege, H.L.; Burgerhof, J.G.M.; Navis, G.; De Zeeuw, D.; De Jong, P.E. Cardiovascular Risk Factors Are Differently Associated with Urinary Albumin Excretion in Men and Women. J. Am. Soc. Nephrol. 2003, 14, 1330-1335. [CrossRef] [PubMed]

32. De Zeeuw, D.; Parving, H.-H.; Henning, R.H. Microalbuminuria as an Early Marker for Cardiovascular Disease. J. Am. Soc. Nephrol. 2006, 17, 2100-2105. [CrossRef]

33. Fu, J.; Lee, K.; Chuang, P.Y.; Liu, Z.; He, J.C. Glomerular endothelial cell injury and cross talk in diabetic kidney disease. Am. J. Physiol. Physiol. 2015, 308, F287-F297. [CrossRef] [PubMed]

34. Satchell, S.C.; Tooke, J.E. What is the mechanism of microalbuminuria in diabetes: A role for the glomerular endothelium? Diabetologia 2008, 51, 714-725. [CrossRef] [PubMed]

35. Williams, M.E. Diabetic Nephropathy: The Proteinuria Hypothesis. Am. J. Nephrol. 2005, 25, 77-94. [CrossRef]

36. Jensen, J.S.; Borch-Johnsen, K.; Jensen, G.; Feldt-Rasmussen, B. Microalbuminuria Reflects a Generalized Transvascular Albumin Leakiness in Clinically Healthy Subjects. Clin. Sci. 1995, 88, 629-633. [CrossRef]

37. Su, J.; Ye, D.; Gao, C.; Huang, Q.; Gui, D. Mechanism of progression of diabetic kidney disease mediated by podocyte mitochondrial injury. Mol. Biol. Rep. 2020, 47, 8023-8035. [CrossRef] 
38. Podgórski, P.; Konieczny, A.; Lis, Ł.; Witkiewicz, W.; Hruby, Z. Glomerular podocytes in diabetic renal disease. Adv. Clin. Exp. Med. 2019, 28, 1711-1715. [CrossRef]

39. Xiong, W.; Meng, X.-F.; Zhang, C. Inflammasome activation in podocytes: A new mechanism of glomerular diseases. Inflamm. Res. 2020, 69, 731-743. [CrossRef]

40. Tojo, A.; Onozato, M.L.; Ha, H.; Kurihara, H.; Sakai, T.; Goto, A.; Fujita, T.; Endou, H. Reduced albumin reabsorption in the proximal tubule of early-stage diabetic rats. Histochem. Cell Biol. 2001, 116, 269-276. [CrossRef] [PubMed]

41. Russo, L.M.; Sandoval, R.M.; Campos, S.B.; Molitoris, B.A.; Comper, W.D.; Brown, D. Impaired Tubular Uptake Explains Albuminuria in Early Diabetic Nephropathy. J. Am. Soc. Nephrol. 2008, 20, 489-494. [CrossRef]

42. Russo, L.; Sandoval, R.; McKee, M.; Osicka, T.; Collins, A.; Brown, D.; Molitoris, B.; Comper, W. The normal kidney filters nephrotic levels of albumin retrieved by proximal tubule cells: Retrieval is disrupted in nephrotic states. Kidney Int. 2007, 71, 504-513. [CrossRef]

43. Jenkin, K.A.; Verty, A.N.; McAinch, A.J.; Hryciw, D.H. Endocannabinoids and the renal proximal tubule: An emerging role in diabetic nephropathy. Int. J. Biochem. Cell Biol. 2012, 44, 2028-2031. [CrossRef] [PubMed]

44. Cozzolino, D.; Sessa, G.; Salvatore, T.; Sasso, F.C.; Giugliano, D.; Lefèbvre, P.J.; Torella, R. The involvement of the opioid system in human obesity: A study in normal weight relatives of obese people. J. Clin. Endocrinol. Metab. 1996, 81, 713-718. [CrossRef]

45. Leung, J.C. Diabetic Tubulopathy: An Emerging Entity. Contrib. Nephrol. 2011, 170, 124-134. [CrossRef]

46. Notice. Kidney Int. Suppl. 2013, 3, 1. [CrossRef]

47. Hillege, H.L.; Fidler, V.; Diercks, G.F.; Van Gilst, W.H.; De Zeeuw, D.; Van Veldhuisen, D.J.; Gans, R.O.; Janssen, W.M.; Grobbee, D.E.; De Jong, P.E. Urinary Albumin Excretion Predicts Cardiovascular and Noncardiovascular Mortality in General Population. Circulation 2002, 106, 1777-1782. [CrossRef] [PubMed]

48. Matsushita, K.; Van Der Velde, M.; Astor, B.C.; Woodward, M.; Levey, A.S.; De Jong, P.E.; Coresh, J.; Gansevoort, R.T. Association of estimated glomerular filtration rate and albuminuria with all-cause and cardiovascular mortality in general population cohorts: A collaborative meta-analysis. Lancet 2010, 375, 2073-2081. [CrossRef]

49. Ninomiya, T.; Perkovic, V.; De Galan, B.E.; Zoungas, S.; Pillai, A.; Jardine, M.; Patel, A.; Cass, A.; Neal, B.; Poulter, N.; et al. Albuminuria and Kidney Function Independently Predict Cardiovascular and Renal Outcomes in Diabetes. J. Am. Soc. Nephrol. 2009, 20, 1813-1821. [CrossRef]

50. Astor, B.C.; The Chronic Kidney Disease Prognosis Consortium; Matsushita, K.; Gansevoort, R.T.; Van Der Velde, M.; Woodward, M.; Levey, A.S.; De Jong, P.E.; Coresh, J. Lower estimated glomerular filtration rate and higher albuminuria are associated with mortality and end-stage renal disease. A collaborative meta-analysis of kidney disease population cohorts. Kidney Int. 2011, 79, 1331-1340. [CrossRef] [PubMed]

51. Gansevoort, R.T.; Matsushita, K.; Van Der Velde, M.; Astor, B.C.; Woodward, M.; Levey, A.S.; De Jong, P.E.; Coresh, J. Lower estimated GFR and higher albuminuria are associated with adverse kidney outcomes. A collaborative meta-analysis of general and high-risk population cohorts. Kidney Int. 2011, 80, 93-104. [CrossRef]

52. De Nicola, L.; Zoccali, C. Chronic kidney disease prevalence in the general population: Heterogeneity and concerns: Table 1. Nephrol. Dial. Transplant. 2016, 31, 331-335. [CrossRef]

53. Mann, J.F.; Yi, Q.-L.; Gerstein, H.C.E.; Mann, Q.-L.Y.J.F. Albuminuria as a predictor of cardiovascular and renal outcomes in people with known atherosclerotic cardiovascular disease. Kidney Int. 2004, 66, S59-S62. [CrossRef]

54. Van Der Velde, M.; The Chronic Kidney Disease Prognosis Consortium; Matsushita, K.; Coresh, J.; Astor, B.C.; Woodward, M.; Levey, A.S.; De Jong, P.E.; Gansevoort, R.T. Lower estimated glomerular filtration rate and higher albuminuria are associated with all-cause and cardiovascular mortality. A collaborative meta-analysis of high-risk population cohorts. Kidney Int. 2011, 79, 1341-1352. [CrossRef]

55. Nayor, M.; Larson, M.G.; Wang, N.; Santhanakrishnan, R.; Lee, D.S.; Tsao, C.W.; Cheng, S.; Benjamin, E.J.; Vasan, R.S.; Levy, D.; et al. The association of chronic kidney disease and microalbuminuria with heart failure with preserved vs. reduced ejection fraction. Eur. J. Heart Fail. 2017, 19, 615-623. [CrossRef] [PubMed]

56. Wattanakit, K.; Folsom, A.R.; Criqui, M.H.; Kramer, H.J.; Cushman, M.; Shea, S.; Hirsch, A.T. Albuminuria and peripheral arterial disease: Results from the Multi-Ethnic Study of Atherosclerosis (MESA). Atherosclerosis 2008, 201, 212-216. [CrossRef]

57. Scirica, B.M.; Mosenzon, O.; Bhatt, D.L.; Jacob, A.U.; Steg, P.G.; McGuire, D.K.; Im, K.; Kanevsky, E.; Stahre, C.; Sjöstrand, M.; et al. Cardiovascular Outcomes According to Urinary Albumin and Kidney Disease in Patients With Type 2 Diabetes at High Cardiovascular Risk. JAMA Cardiol. 2018, 3, 155-163. [CrossRef] [PubMed]

58. De Zeeuw, D.; Remuzzi, G.; Parving, H.-H.; Keane, W.F.; Zhang, Z.; Shahinfar, S.; Snapinn, S.; Cooper, M.E.; Mitch, W.E.; Brenner, B.M. Albuminuria, a Therapeutic Target for Cardiovascular Protection in Type 2 Diabetic Patients With Nephropathy. Circulation 2004, 110, 921-927. [CrossRef]

59. Abbate, M.; Zoja, C.; Remuzzi, G. How Does Proteinuria Cause Progressive Renal Damage? J. Am. Soc. Nephrol. 2006, 17, 2974-2984. [CrossRef] [PubMed]

60. Carrero, J.J.; Grams, M.E.; Sang, Y.; Ärnlöv, J.; Gasparini, A.; Matsushita, K.; Qureshi, A.R.; Evans, M.; Barany, P.; Lindholm, B.; et al. Albuminuria changes are associated with subsequent risk of end-stage renal disease and mortality. Kidney Int. 2017, 91, 244-251. [CrossRef]

61. Ruggenenti, P.; Perna, A.; Mosconi, L.; Pisoni, R.; Remuzzi, G. Urinary protein excretion rate is the best independent predictor of ESRF in non-diabetic proteinuric chronic nephropathies. Kidney Int. 1998, 53, 1209-1216. [CrossRef] 
62. Heerspink, H.J.L.; Ninomiya, T.; Persson, F.; Brenner, B.M.; Brunel, P.; Chaturvedi, N.; Desai, A.S.; Haffner, S.M.; McMurray, J.J.V.; Solomon, S.D.; et al. Is a reduction in albuminuria associated with renal and cardiovascular protection? Apost hocanalysis of the ALTITUDE trial. Diabetes Obes. Metab. 2015, 18, 169-177. [CrossRef]

63. De Zeeuw, D.; Remuzzi, G.; Parving, H.-H.; Keane, W.F.; Zhang, Z.; Shahinfar, S.; Snapinn, S.; Cooper, M.E.; Mitch, W.E.; Brenner, B.M. Proteinuria, a target for renoprotection in patients with type 2 diabetic nephropathy: Lessons from RENAAL. Kidney Int. 2004, 65, 2309-2320. [CrossRef] [PubMed]

64. Atkins, R.C.; Briganti, E.M.; Lewis, J.B.; Hunsicker, L.G.; Braden, G.; De Crespigny, P.J.C.; Deferrari, G.; Drury, P.; Locatelli, F.; Wiegmann, T.B.; et al. Proteinuria reduction and progression to renal failure in patients with type 2 diabetes mellitus and overt nephropathy. Am. J. Kidney Dis. 2005, 45, 281-287. [CrossRef]

65. Minutolo, R.; Gabbai, F.B.; Provenzano, M.; Chiodini, P.; Borrelli, S.; Garofalo, C.; Sasso, F.C.; Santoro, D.; Bellizzi, V.; Conte, G.; et al. Cardiorenal prognosis by residual proteinuria level in diabetic chronic kidney disease: Pooled analysis of four cohort studies. Nephrol. Dial. Transplant. 2018, 33, 1942-1949. [CrossRef]

66. Provenzano, M.; Chiodini, P.; Minutolo, R.; Zoccali, C.; Bellizzi, V.; Conte, G.; Locatelli, F.; Tripepi, G.; Del Vecchio, L.; Mallamaci, F.; et al. Reclassification of chronic kidney disease patients for end-stage renal disease risk by proteinuria indexed to estimated glomerular filtration rate: Multicentre prospective study in nephrology clinics. Nephrol. Dial. Transplant. 2018, 35, 138-147. [CrossRef] [PubMed]

67. Cravedi, P.; Ruggenenti, P.; Remuzzi, G. Proteinuria should be used as a surrogate in CKD. Nat. Rev. Nephrol. 2012, 8, 301-306. [CrossRef]

68. Sumida, K.; Molnar, M.Z.; Potukuchi, P.K.; George, K.; Thomas, F.; Lu, J.L.; Yamagata, K.; Kalantar-Zadeh, K.; Kovesdy, C.P. Changes in Albuminuria and Subsequent Risk of Incident Kidney Disease. Clin. J. Am. Soc. Nephrol. 2017, 12, 1941-1949. [CrossRef] [PubMed]

69. Heerspink, H.J.L.; Kröpelin, T.F.; Hoekman, J.; De Zeeuw, D. Drug-Induced Reduction in Albuminuria Is Associated with Subsequent Renoprotection: A Meta-Analysis. J. Am. Soc. Nephrol. 2014, 26, 2055-2064. [CrossRef]

70. Inker, L.A.; Levey, A.S.; Pandya, K.; Stoycheff, N.; Okparavero, A.; Greene, T.; Chronic Kidney Disease Epidemiology Collaboration (CKD-EPI). Early Change in Proteinuria as a Surrogate End Point for Kidney Disease Progression: An Individual Patient Meta-analysis. Am. J. Kidney Dis. 2014, 64, 74-85. [CrossRef]

71. Coresh, J.; Heerspink, H.J.L.; Sang, Y.; Matsushita, K.; Arnlov, J.; Astor, B.C.; Black, C.; Brunskill, N.J.; Carrero, J.-J.I.; Feldman, H.; et al. Change in albuminuria and subsequent risk of end-stage kidney disease: An individual participant-level consortium meta-analysis of observational studies. Lancet Diabetes Endocrinol. 2019, 7, 115-127. [CrossRef]

72. Jun, M.; Ohkuma, T.; Zoungas, S.; Colagiuri, S.; Mancia, G.; Marre, M.; Matthews, D.; Poulter, N.; Williams, B.; Rodgers, A.; et al. Changes in Albuminuria and the Risk of Major Clinical Outcomes in Diabetes: Results From ADVANCE-ON. Diabetes Care 2017, 41, 163-170. [CrossRef] [PubMed]

73. Chan, G.C.; Tang, S.C. Diabetic nephropathy: Landmark clinical trials and tribulations. Nephrol. Dial. Transplant. 2016, 31, 359-368. [CrossRef]

74. Heerspink, H.J.; Greene, T.; Tighiouart, H.; Gansevoort, R.T.; Coresh, J.; Simon, A.L.; Chan, T.M.; Hou, F.F.; Lewis, J.B.; Locatelli, F.; et al. Change in albuminuria as a surrogate endpoint for progression of kidney disease: A meta-analysis of treatment effects in randomised clinical trials. Lancet Diabetes Endocrinol. 2019, 7, 128-139. [CrossRef]

75. Parving, H.-H.; Lambers-Heerspink, H.; De Zeeuw, D. Empagliflozin and Progression of Kidney Disease in Type 2 Diabetes. N. Engl. J. Med. 2016, 375, 1799-1802. [CrossRef]

76. Perkovic, V.; De Zeeuw, D.; Mahaffey, K.W.; Fulcher, G.; Erondu, N.; Shaw, W.; Barrett, T.D.; Weidner-Wells, M.; Deng, H.; Matthews, D.R.; et al. Canagliflozin and renal outcomes in type 2 diabetes: Results from the CANVAS Program randomised clinical trials. Lancet Diabetes Endocrinol. 2018, 6, 691-704. [CrossRef]

77. Mosenzon, O.; Wiviott, S.D.; Cahn, A.; Rozenberg, A.; Yanuv, I.; Goodrich, E.L.A.; Murphy, S.; Heerspink, H.J.L.A.; Zelniker, T.; Dwyer, J.P.; et al. Effects of dapagliflozin on development and progression of kidney disease in patients with type 2 diabetes: An analysis from the DECLARE-TIMI 58 randomised trial. Lancet Diabetes Endocrinol. 2019, 7, 606-617. [CrossRef]

78. Perkovic, V.; Jardine, M.J.; Neal, B.; Bompoint, S.; Heerspink, H.J.; Charytan, D.M.; Edwards, R.; Agarwal, R.; Bakris, G.; Bull, S.; et al. Canagliflozin and Renal Outcomes in Type 2 Diabetes and Nephropathy. N. Engl. J. Med. 2019, 380, 2295-2306. [CrossRef]

79. Giugliano, D.; Ceriello, A.; De Nicola, L.; Perrone-Filardi, P.; Cosentino, F.; Esposito, K. Primary versus secondary cardiorenal prevention in type 2 diabetes: Which newer anti-hyperglycaemic drug matters? Diabetes Obes. Metab. 2020, 22, 149-157. [CrossRef]

80. Giugliano, D.; De Nicola, L.; Maiorino, M.I.; Bellastella, G.; Garofalo, C.; Chiodini, P.; Ceriello, A.; Esposito, K. Preventing major adverse cardiovascular events by SGLT-2 inhibition in patients with type 2 diabetes: The role of kidney. Cardiovasc. Diabetol. 2020, 19, 1-6. [CrossRef]

81. Oshima, M.; Neuen, B.L.; Li, J.; Perkovic, V.; Charytan, D.M.; De Zeeuw, D.; Edwards, R.; Greene, T.; Levin, A.; Mahaffey, K.W.; et al. Early Change in Albuminuria with Canagliflozin Predicts Kidney and Cardiovascular Outcomes: A PostHoc Analysis from the CREDENCE Trial. J. Am. Soc. Nephrol. 2020, 31, 2925-2936. [CrossRef]

82. Neuen, B.L.; Ohkuma, T.; Neal, B.; Matthews, D.R.; De Zeeuw, D.; Mahaffey, K.W.; Fulcher, G.; Li, Q.; Jardine, M.; Oh, R.; et al. Effect of Canagliflozin on Renal and Cardiovascular Outcomes across Different Levels of Albuminuria: Data from the CANVAS Program. J. Am. Soc. Nephrol. 2019, 30, 2229-2242. [CrossRef] 
83. Heerspink, H.J.L.; Parving, H.-H.; Andress, D.L.; Bakris, G.; Correa-Rotter, R.; Hou, F.-F.; Kitzman, D.W.; Kohan, D.; Makino, H.; McMurray, J.J.V.; et al. Atrasentan and renal events in patients with type 2 diabetes and chronic kidney disease (SONAR): A double-blind, randomised, placebo-controlled trial. Lancet 2019, 393, 1937-1947. [CrossRef]

84. Heerspink, H.J.; Kohan, D.E.; de Zeeuw, D. New insights from SONAR indicate adding sodium glucose co-transporter 2 inhibitors to an endothelin receptor antagonist mitigates fluid retention and enhances albuminuria reduction. Kidney Int. 2021, 99, 346-349. [CrossRef] [PubMed]

85. Bakris, G.L.; Agarwal, R.; Anker, S.D.; Pitt, B.; Ruilope, L.M.; Rossing, P.; Kolkhof, P.; Nowack, C.; Schloemer, P.; Joseph, A.; et al. Effect of Finerenone on Chronic Kidney Disease Outcomes in Type 2 Diabetes. N. Engl. J. Med. 2020, 383, 2219-2229. [CrossRef]

86. Levey, A.S.; Inker, L.A.; Matsushita, K.; Greene, T.; Willis, K.; Lewis, E.; De Zeeuw, D.; Cheung, A.K.; Coresh, J. GFR Decline as an End Point for Clinical Trials in CKD: A Scientific Workshop Sponsored by the National Kidney Foundation and the US Food and Drug Administration. Am. J. Kidney Dis. 2014, 64, 821-835. [CrossRef]

87. Waugh, N.; Robertson, A. Protein restriction for diabetic renal disease. Cochrane Database Syst. Rev. 1997, 4, CD002181. [CrossRef]

88. Bellizzi, V.; Di Iorio, B.; De Nicola, L.; Minutolo, R.; Zamboli, P.; Trucillo, P.; Catapano, F.; Di Cristofano, C.; Scalfi, L.; Conte, G.; et al. Very low protein diet supplemented with ketoanalogs improves blood pressure control in chronic kidney disease. Kidney Int. 2007, 71, 245-251. [CrossRef]

89. Aparicio, M.; Bellizzi, V.; Chauveau, P.; Cupisti, A.; Ecder, T.; Fouque, D.; Garneata, L.; Lin, S.; Mitch, W.; Teplan, V.; et al. Do Ketoanalogues Still Have a Role in Delaying Dialysis Initiation in CKD Predialysis Patients? Semin. Dial. 2013, 26, 714-719. [CrossRef] [PubMed]

90. Bellizzi, V.; Calella, P.; Hernández, J.N.; González, V.F.; Lira, S.M.; Torraca, S.; Arronte, R.U.; Cirillo, P.; Minutolo, R.; Cárdenas, R.A.M. Safety and effectiveness of low-protein diet supplemented with ketoacids in diabetic patients with chronic kidney disease. BMC Nephrol. 2018, 19, 110. [CrossRef] [PubMed]

91. Ikizler, T.A.; Burrowes, J.D.; Byham-Gray, L.D.; Campbell, K.L.; Carrero, J.-J.; Chan, W.; Fouque, D.; Friedman, A.N.; Ghaddar, S.; Goldstein-Fuchs, D.J.; et al. KDOQI Clinical Practice Guideline for Nutrition in CKD: 2020 Update. Am. J. Kidney Dis. 2020, 76, S1-S107. [CrossRef]

92. Li, X.-F.; Xu, J.; Liu, L.-J.; Wang, F.; He, S.-L.; Su, Y.; Dong, C.-P. Efficacy of low-protein diet in diabetic nephropathy: A meta-analysis of randomized controlled trials. Lipids Health Dis. 2019, 18, 82. [CrossRef]

93. Bellizzi, V.; Cupisti, A.; Locatelli, F.; Bolasco, P.; Brunori, G.; Cancarini, G.; Caria, S.; De Nicola, L.; Di Iorio, B.R.; Di Micco, L.; et al. Low-protein diets for chronic kidney disease patients: The Italian experience. BMC Nephrol. 2016, 17, 77. [CrossRef] [PubMed]

94. Kalantar-Zadeh, K.; Fouque, D. Nutritional Management of Chronic Kidney Disease. N. Engl. J. Med. 2017, 377, 1765-1776. [CrossRef] [PubMed]

95. Li, Q.; Wen, F.; Wang, Y.; Li, S.; Lin, S.; Qi, C.; Chen, Z.; Qiu, X.; Zhang, Y.; Zhang, S.; et al. Diabetic Kidney Disease Benefits from Intensive Low-Protein Diet: Updated Systematic Review and Meta-analysis. Diabetes Ther. 2021, 12, 21-36. [CrossRef]

96. Nezu, U.; Kamiyama, H.; Kondo, Y.; Sakuma, M.; Morimoto, T.; Ueda, S. Effect of low-protein diet on kidney function in diabetic nephropathy: Meta-analysis of randomised controlled trials. BMJ Open 2013, 3, e002934. [CrossRef] [PubMed]

97. He, J.; Mills, K.T.; Appel, L.J.; Yang, W.; Chen, J.; Lee, B.T.; Rosas, S.E.; Porter, A.; Makos, G.; Weir, M.R.; et al. Urinary Sodium and Potassium Excretion and CKD Progression. J. Am. Soc. Nephrol. 2015, 27, 1202-1212. [CrossRef]

98. Slagman, M.C.J.; Waanders, F.; Hemmelder, M.H.; Woittiez, A.-J.; Janssen, W.M.T.; Heerspink, H.J.L.; Navis, G.; Laverman, G.D.; The HONEST (HOlland NEphrology STudy) Group. Moderate dietary sodium restriction added to angiotensin converting enzyme inhibition compared with dual blockade in lowering proteinuria and blood pressure: Randomised controlled trial. BMJ 2011, 343, d4366. [CrossRef]

99. McMahon, E.J.; Bauer, J.D.; Hawley, C.M.; Isbel, N.M.; Stowasser, M.; Johnson, D.W.; Campbell, K.L. A Randomized Trial of Dietary Sodium Restriction in CKD. J. Am. Soc. Nephrol. 2013, 24, 2096-2103. [CrossRef]

100. Kwakernaak, A.J.; Krikken, J.A.; Binnenmars, S.H.; Visser, F.W.; Hemmelder, M.H.; Woittiez, A.-J.; Groen, H.; Laverman, G.D.; Navis, G. Effects of sodium restriction and hydrochlorothiazide on RAAS blockade efficacy in diabetic nephropathy: A randomised clinical trial. Lancet Diabetes Endocrinol. 2014, 2, 385-395. [CrossRef]

101. Heerspink, H.J.L.; Holtkamp, F.A.; Parving, H.-H.; Navis, G.J.; Lewis, J.B.; Ritz, E.; De Graeff, P.A.; De Zeeuw, D. Moderation of dietary sodium potentiates the renal and cardiovascular protective effects of angiotensin receptor blockers. Kidney Int. 2012, 82, 330-337. [CrossRef]

102. Garofalo, C.; Borrelli, S.; Provenzano, M.; De Stefano, T.; Vita, C.; Chiodini, P.; Minutolo, R.; De Nicola, L.; Conte, G. Dietary Salt Restriction in Chronic Kidney Disease: A Meta-Analysis of Randomized Clinical Trials. Nutrients 2018, 10, 732. [CrossRef]

103. Effects of ramipril on cardiovascular and microvascular outcomes in people with diabetes mellitus: Results of the HOPE study and MICRO-HOPE substudy. Heart Outcomes Prevention Evaluation Study Investigators. Lancet 2000, 355, 253-259. [CrossRef]

104. Marre, M.; Lievre, M.; Chatellier, G.E.; Mann, J.F.; Passa, P.; Ménard, J. Effects of low dose ramipril on cardiovascular and renal outcomes in patients with type 2 diabetes and raised excretion of urinary albumin: Randomised, double blind, placebo controlled trial (the DIABHYCAR study). BMJ 2004, 328, 495. [CrossRef] [PubMed]

105. Brenner, B.M.; Cooper, M.E.; De Zeeuw, D.; Keane, W.F.; Mitch, W.E.; Parving, H.-H.; Remuzzi, G.; Snapinn, S.M.; Zhang, Z.; Shahinfar, S. Effects of Losartan on Renal and Cardiovascular Outcomes in Patients with Type 2 Diabetes and Nephropathy. N. Engl. J. Med. 2001, 345, 861-869. [CrossRef] 
106. Saglimbene, V.; Palmer, S.C.; Ruospo, M.; Natale, P.; Maione, A.; Nicolucci, A.; Vecchio, M.; Tognoni, G.; Craig, J.C.; Pellegrini, F.; et al. The Long-Term Impact of Renin-Angiotensin System (RAS) Inhibition on Cardiorenal Outcomes (LIRICO): A Randomized, Controlled Trial. J. Am. Soc. Nephrol. 2018, 29, 2890-2899. [CrossRef] [PubMed]

107. Bakris, G.L.; Smith, A.C.; Richardson, D.J.; Hung, E.; Preston, R.; Goldberg, R.; Epstein, M. Impact of an ACE inhibitor and calcium antagonist on microalbuminuria and lipid subfractions in type 2 diabetes: A randomised, multi-centre pilot study. $J$. Hum. Hypertens. 2002, 16, 185-191. [CrossRef]

108. Udell, J.A.; Bhatt, D.L.; Braunwald, E.; Cavender, M.A.; Mosenzon, O.; Steg, P.G.; Davidson, J.A.; Nicolau, J.C.; Corbalan, R.; Hirshberg, B.; et al. Saxagliptin and Cardiovascular Outcomes in Patients With Type 2 Diabetes Mellitus and Moderate or Severe Renal Impairment: Observations From the SAVOR-TIMI 53 Trial. Diabetes Care 2014, 38, dc141850-705. [CrossRef]

109. Cornel, J.H.; Bakris, G.L.; Stevens, S.R.; Alvarsson, M.; Bax, W.A.; Chuang, L.-M.; Engel, S.S.; Lopes, R.D.; McGuire, D.K.; Riefflin, A.; et al. Effect of Sitagliptin on Kidney Function and Respective Cardiovascular Outcomes in Type 2 Diabetes: Outcomes From TECOS. Diabetes Care 2016, 39, 2304-2310. [CrossRef] [PubMed]

110. Mann, J.F.; Fonseca, V.; Mosenzon, O.; Raz, I.; Goldman, B.; Idorn, T.; Von Scholten, B.J.; Poulter, N.R.; The LEADER Publication Committee on behalf of the LEADER Trial Investigators. Response by Mann et al to Letter Regarding Article, "Effects of Liraglutide Versus Placebo on Cardiovascular Events in Patients With Type 2 Diabetes Mellitus and Chronic Kidney Disease: Results From the LEADER Trial". Circulation 2019, 139, e1017-e1018. [CrossRef]

111. Mann, J.F.E.; Hansen, T.; Idorn, T.A.; Leiter, L.; Marso, S.P.; Rossing, P.; Seufert, J.; Tadayon, S.; Vilsbøll, T. Effects of once-weekly subcutaneous semaglutide on kidney function and safety in patients with type 2 diabetes: A post-hoc analysis of the SUSTAIN 1-7 randomised controlled trials. Lancet Diabetes Endocrinol. 2020, 8, 880-893. [CrossRef]

112. Gerstein, H.C.; Colhoun, H.M.; Dagenais, G.R.; Diaz, R.; Lakshmanan, M.; Pais, P.; Probstfield, J.; Botros, F.T.; Riddle, M.C.; Rydén, L.; et al. Dulaglutide and renal outcomes in type 2 diabetes: An exploratory analysis of the REWIND randomised, placebo-controlled trial. Lancet 2019, 394, 131-138. [CrossRef]

113. Waijer, S.W.; Xie, D.; Inzucchi, S.E.; Zinman, B.; Koitka-Weber, A.; Mattheus, M.; Von Eynatten, M.; Inker, L.A.; Wanner, C.; Heerspink, H.J.L. Short-Term Changes in Albuminuria and Risk of Cardiovascular and Renal Outcomes in Type 2 Diabetes Mellitus: A Post Hoc Analysis of the EMPA-REG OUTCOME Trial. J. Am. Heart Assoc. 2020, 9. [CrossRef]

114. Neal, B.; Perkovic, V.; Mahaffey, K.W.; De Zeeuw, D.; Fulcher, G.; Erondu, N.; Shaw, W.; Law, G.; Desai, M.; Matthews, D.R. Canagliflozin and Cardiovascular and Renal Events in Type 2 Diabetes. N. Engl. J. Med. 2017, 377, 644-657. [CrossRef] [PubMed]

115. Wiviott, S.D.; Raz, I.; Bonaca, M.P.; Mosenzon, O.; Kato, E.T.; Cahn, A.; Silverman, M.G.; Zelniker, T.A.; Kuder, J.F.; Murphy, S.A.; et al. Dapagliflozin and Cardiovascular Outcomes in Type 2 Diabetes. N. Engl. J. Med. 2019, 380, 347-357. [CrossRef]

116. Petrykiv, S.I.; Laverman, G.D.; De Zeeuw, D.; Heerspink, H.J.L. The albuminuria-lowering response to dapagliflozin is variable and reproducible among individual patients. Diabetes Obes. Metab. 2017, 19, 1363-1370. [CrossRef] 